\title{
Semipolar InGaN-based superluminescent diodes for solid-state lighting and visible light communications
}

\author{
Chao Shen ${ }^{\mathrm{a}}$, Tien Khee Nga ${ }^{\mathrm{a}}$, Changmin Lee ${ }^{\mathrm{b}}$, John T. Leonard ${ }^{\mathrm{b}}$, Shuji Nakamura ${ }^{\mathrm{b}}$, James S. Speck \\ Steven P. Denbaars ${ }^{\mathrm{b}}$, Ahmed Y. Alyamanic ${ }^{\mathrm{c}}$, Munir M. El-Desouki ${ }^{\mathrm{c}}$, Boon S. Ooi*a \\ aPhotonics Laboratory, King Abdullah University of Science and Technology (KAUST), Thuwal, \\ Saudi Arabia 21534 \\ ${ }^{\mathrm{b}}$ Materials Department, University of California Santa Barbara (UCSB), Engineering Building II, \\ Santa Barbara, CA, USA 93106 \\ ${ }^{c}$ King Abdulaziz City for Science and Technology (KACST), Riyadh, Saudi Arabia 11442
}

\begin{abstract}
III-nitride light emitters, such as light-emitting diodes (LEDs) and laser diodes (LDs), have been demonstrated and studied for solid-state lighting (SSL) and visible-light communication (VLC) applications. However, for III-nitride LEDbased SSL-VLC system, its efficiency is limited by the "efficiency droop" effect and the high-speed performance is limited by a relatively small $-3 \mathrm{~dB}$ modulation bandwidth $(<100 \mathrm{MHz})$. InGaN-based LDs were recently studied as a droop-free, high-speed emitter; yet it is associated with speckle-noise and safety concerns. In this paper, we presented the semipolar InGaN-based violet-blue emitting superluminescent diodes (SLDs) as a high-brightness and high-speed light source, combining the advantages of LEDs and LDs. Utilizing the integrated passive absorber configuration, an InGaN/GaN quantum well (QW) based SLD was fabricated on semipolar GaN substrate. Using SLD to excite a YAG:Ce phosphor, white light can be generated, exhibiting a color rendering index of 68.9 and a color temperature of $4340 \mathrm{~K}$. Besides, the opto-electrical properties of the SLD, the emission pattern of the phosphor-converted white light, and the high-speed $(\mathrm{Gb} / \mathrm{s})$ visible light communication link using SLD as the transmitter have been presented and discussed in this paper.
\end{abstract}

Keywords: Amplified spontaneous emission, gallium nitride, InGaN, laser diode, light-emitting diode, superluminescent diodes, solid-state lighting, visible light communication

\section{INTRODUCTION}

The development of InGaN/GaN quantum well (QW) based violet-blue-green light-emitting diodes (LEDs) [1-6] and laser diodes (LDs) [7-10] enables efficient solid-state lighting (SSL) technology for a wider range of applications, such as general illumination, automotive lighting, display and horticulture [11, 12]. Besides, the utilization of III-nitride LEDs and LDs as the transmitter for free-space visible light communications (VLC) and underwater wireless optical communications (UWOC) has been demonstrated and investigated recently [13-16]. Compared to the conventional radio frequency (RF) communication techniques, VLC shows many potential advantages, such as unregulated channels, avoiding electromagnetic interference (EMI), high security and low-cost [13, 15]. Hence, by combining GaN-based LEDs or LDs with phosphors, the white light bulb can be achieved for SSL and VLC functionalities [12, 15].

Though high-efficient GaN-based LEDs and LDs have been studied for high-power and high-speed SSL-VLC applications, there are performance-limiting concerns to be resolved. For example, InGaN/GaN QW LEDs suffers from the "efficiency droop" effect, resulting in a rapidly reduced efficiency at high current injections $[4,5]$. Also, a relatively small modulation bandwidth of LEDs limits the data communication rate in LED-based VLC links. As for LDs, the efficiency droop is not presented, and a much higher modulation bandwidth is measured. However, the LD-based light bulb is associated with speckle noise and safety concerns [17]. The GaN superluminescent diodes (SLDs), which combine the advantages of both LEDs and LDs, have shown great potentials for SSL-VLC applications [18].

*boon.ooi@kaust.edu.sa; phone 966-544700036; fax 966-128084350; photonics.kaust.edu.sa

Gallium Nitride Materials and Devices XII, edited by Jen-Inn Chyi, Hiroshi Fujioka, Hadis Morkoç,

Yasushi Nanishi, Ulrich T. Schwarz, Jong-In Shim, Proc. of SPIE Vol. 10104, 101041U

(C) 2017 SPIE $\cdot$ CCC code: $0277-786 X / 17 / \$ 18 \cdot$ doi: 10.1117/12.2251144 
As a time incoherent but a spatial coherent light source, SLDs, which operate in the amplified spontaneous emission (ASE) regime, have been used for a number of attractive applications, such as optical coherence tomography (OCT), fiber optic gyroscope (FOG), and fiber-optic sensor [18-20]. More recently, the violet-blue emitting InGaN/GaN QW based superluminescent diodes have been reported, which are the essential components for SSL system. Table 1 summarizes the design and performance of the demonstrated GaN-based SLDs, comparing the emission wavelength, substrate material, configuration, waveguide design, and the maximum light output power reported in each case.

Table 1. Summary of advances of InGaN-based SLDs.

\begin{tabular}{|c|c|c|c|c|c|}
\hline Emission wavelength & Substrate material & Configuration & Waveguide design & Optical power & Reference \\
\hline $405 \mathrm{~nm}$ & Semipolar GaN & tilted facet & $4 \mu \mathrm{m}$ ridge & $20 \mathrm{~mW}(\mathrm{cw})$ & [21] \\
\hline $405 \mathrm{~nm}$ & $c-\mathrm{GaN}$ & tilted waveguide & $3 \mu \mathrm{m}$ ridge & $0.65 \mathrm{~mW}$ (pulse) & [22] \\
\hline $405 \mathrm{~nm}$ & $c-\mathrm{GaN}$ & passive absorber & $3 / 10 \mu \mathrm{m}$ ridge & $25 \mathrm{~mW}$ & {$[23]$} \\
\hline $405 \mathrm{~nm}$ & $c-\mathrm{GaN}$ & tilted waveguide & $3 / 10 \mu \mathrm{m}$ ridge & $125 \mathrm{~mW}$ & {$[23]$} \\
\hline $405 \mathrm{~nm}$ & $c-\mathrm{GaN}$ & "j-shape" waveguide & curved ridge & $350 \mathrm{~mW}(\mathrm{cw})$ & [24] \\
\hline $408 \mathrm{~nm}$ & $c-\mathrm{GaN}$ & "j-shape" waveguide & "j-shape" ridge & $200 \mathrm{~mW}(\mathrm{cw})$ & {$[25]$} \\
\hline $410 \sim 445 \mathrm{~nm}$ & $c-\mathrm{GaN}$ & tilted waveguide & $2 \mu \mathrm{m}$ ridge & $30 \sim 55 \mathrm{~mW}(\mathrm{cw})$ & {$[26]$} \\
\hline $420 \mathrm{~nm}$ & $c-\mathrm{GaN}$ & tilted facet & $2 \mu \mathrm{m}$ ridge & $\begin{array}{c}2 \mathrm{~mW}(\mathrm{cw}) \\
100 \mathrm{~mW} \text { (pulse) }\end{array}$ & [27] \\
\hline $420 \mathrm{~nm}$ & $c-\mathrm{GaN}$ & $\begin{array}{l}\text { "j-shape" waveguide } \\
\text { AR/HR coating }\end{array}$ & $3 \mu \mathrm{m}$ ridge & $200 \mathrm{~mW}(\mathrm{cw})$ & [28] \\
\hline $439 \mathrm{~nm}$ & $m-\mathrm{GaN}$ & facet roughening & $4 \mu \mathrm{m}$ ridge & $5 \mathrm{~mW}$ (pulse) & [29] \\
\hline $443 \mathrm{~nm}$ & $c-\mathrm{GaN}$ & curved waveguide & $2 \mu \mathrm{m}$ ridge & $100 \mathrm{~mW}(\mathrm{cw})$ & {$[30]$} \\
\hline $445 \mathrm{~nm}$ & $c-\mathrm{GaN}$ & oblique facet & $5 \mu \mathrm{m}$ ridge & - & {$[31]$} \\
\hline $447 \mathrm{~nm}$ & Semipolar GaN & passive absorber & $7.5 \mu \mathrm{m}$ ridge & $256 \mathrm{~mW}(\mathrm{cw})$ & {$[17]$} \\
\hline $500 \mathrm{~nm}$ & $c-\mathrm{GaN}$ & curved waveguide & $2 \mu \mathrm{m}$ ridge & $4 \mathrm{~mW}$ (pulse) & {$[32]$} \\
\hline
\end{tabular}

Since most of InGaN/GaN QW SLDs are grown on a polar, c-plane GaN substrate, there is a growing interest to develop high efficient violet-blue SLDs on nonpolar or semipolar substrates owing to a reduced polarization field presented in the QW structure [2]. Studies on semipolar and nonpolar GaN-based LEDs and LDs have revealed that the enhanced electron and hole wavefunction overlap is expected for InGaN/GaN QWs grown on nonpolar ( $m$-plane) and semipolar GaN substrates, leading to an enhanced internal quantum efficiency [2,3]. Therefore, the presented study focuses on SLDs grown on semipolar GaN substrate.

In this paper, the electrical and spectral characteristics of the semipolar InGaN/GaN QW based SLD will be presented and discussed. The SLD is utilized to generate white light by exciting a commercially available YAG:Ce phosphor for SSL applications. The emission properties were discussed by comparing the performance with that of the LED and LD based white light. Finally, the utilization of SLD as a high-speed transmitter for VLC system is demonstrated.

\section{BLUE EMITTING INGAN/GAN QUANTUM WELL SUPERLUMINESCENT DIODE}

The blue emitting InGaN/GaN QW SLD on semipolar GaN substrate has been demonstrated, and its emission characteristics are measured at room temperature. Figure 1 shows the 3D schematic of the device structure. The SLD is constructed using an integrated passive absorber configuration, so the oscillations of light in the resonating cavity structure are suppressed to avoid lasing. The epitaxial structure of demonstrated SLD structure was grown on a semipolar $(20 \overline{21})$ bulk GaN substrate from Mitsubishi Chemical Corporation using metal-organic chemical vapor deposition 
(MOCVD) technique. It consisted of a pair of GaN contact layers, a pair of GaN cladding layers, a pair of InGaN separate confinement heterostructure $(\mathrm{SCH})$ waveguiding layers, an $\mathrm{AlGaN}$ electron blocking layer (EBL), and a 4period of $\mathrm{In}_{0.2} \mathrm{Ga}_{0.8} \mathrm{~N}$ multiple QW active region. The detailed layer structure is similar to that in our other reports $[9,17]$. The device has a $700-\mu \mathrm{m}$-long gain region and a $490-\mu \mathrm{m}$-long passive absorber. The SLD is driven by injecting current into the gain region without biasing the absorber.



Figure 1. 3D schematic of the demonstrated InGaN/GaN QW SLD on semipolar GaN substrate. The length of the SLD gain region and the passive absorber are $700 \mu \mathrm{m}$ and $490 \mu \mathrm{m}$, respectively.

The SLD is tested in a customer made prober at room temperature. The setup involves a Keithley 2520 diode tester with a calibrated $\mathrm{Si}$ photodetector and an integrating sphere for electrical characterization. The emission spectra were collected using Ocean Optics HR 4000 high-resolution spectrometer. Figure 2 shows the optical image of the amplified spontaneous emission of the SLD. All the measurements were carried out under DC current injection.

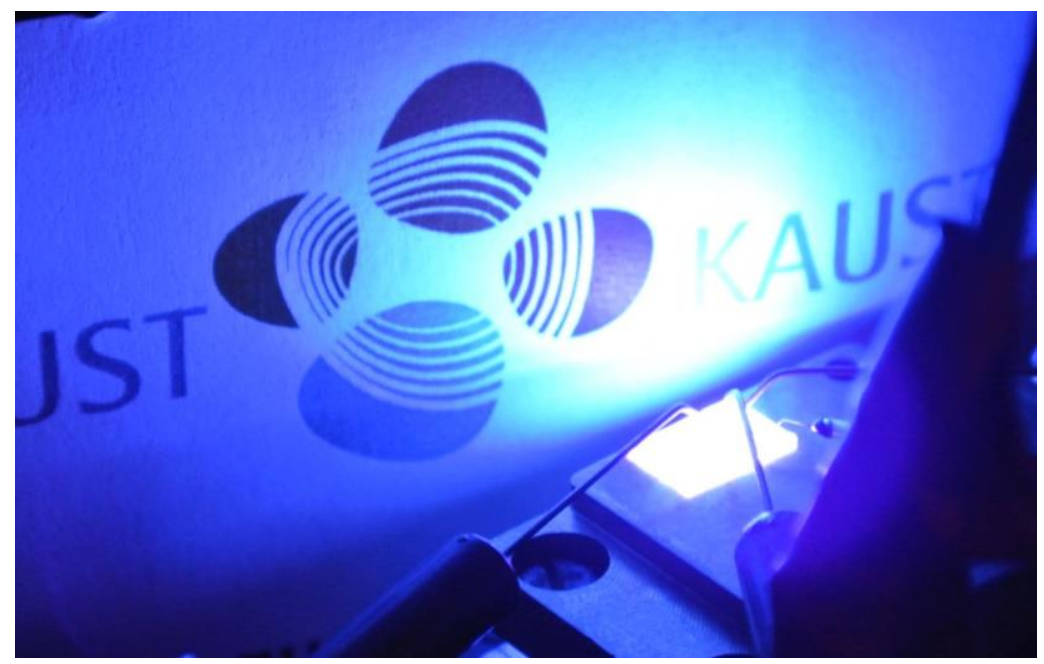

Figure 2. Photo of the amplified spontaneous emission from the blue-emitting SLD under DC injection. 
Figure 3 presents the optical power - injection current - voltage (L-I-V) characteristic of the SLD. The photodetector was placed both at the facet, in-plane to the waveguide, and above the device, normal to the waveguide, in order to measure the optical power of the edge emission and the surface emission, respectively. The former approach measured the amplified spontaneous emission together with the spontaneous emission (ASE+SE) of the SLD while the latter approach measured only the uncoupled, spontaneous emission (SE) from the SLD. By comparing the two curves, a

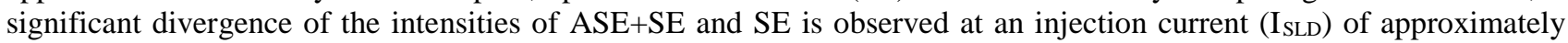
$250 \mathrm{~mA}$, which is the onset of superluminescence. The SLD exhibits a superlinear increase in the intensity at $\mathrm{I}_{\mathrm{SLD}}>250$ $\mathrm{mA}$, which is different than the behavior in LDs, where a linear increase of optical power above the threshold condition is expected. The corresponding forward voltage at $\mathrm{I}_{\mathrm{SLD}}=250 \mathrm{~mA}$ is $6 \mathrm{~V}$. The optical powers of the SLD are $78.0 \mathrm{~mW}$, $122.6 \mathrm{~mW}$, and $202.5 \mathrm{~mW}$ at ISLD $=400 \mathrm{~mA}, 500 \mathrm{~mA}$ and $550 \mathrm{~mA}$, respectively. The high optical power is partially attributed to the improved optical gain of the SLD, originating from a high material gain in InGaN/GaN QWs grown on semipolar GaN substrate.

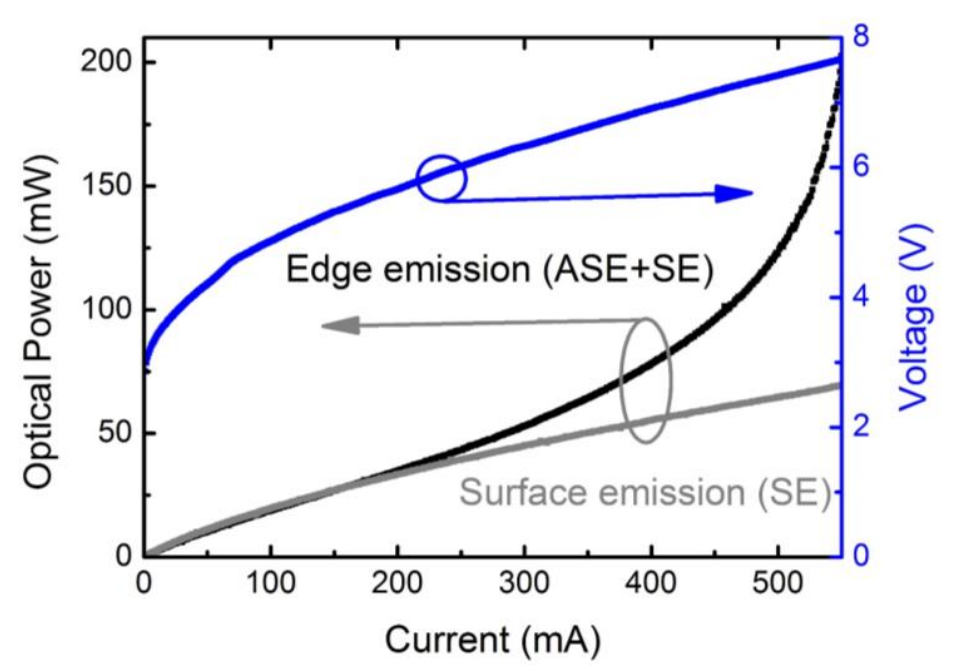

Figure 3. Optical power $v s$. injection current and voltage $v s$. injection current relations of the SLD. The photodetector was placed both on top and at the edge of the SLD to measure the optical powers from the top surface of the device (spontaneous emission, SE only), and from the edge of the device (amplified spontaneous emission and spontaneous emission, ASE+SE), respectively.

The emission spectra of the SLD collected at the edge of the device at an increasing ISLD $_{\text {from }} 100 \mathrm{~mA}$ to $550 \mathrm{~mA}$ are plotted in Figure 4(a). The SLD has a peak emission wavelength of $\sim 450 \mathrm{~nm}$. With increasing ISLD, a narrowing of the emission peak, as well as a slight blueshift of the peak, was observed.
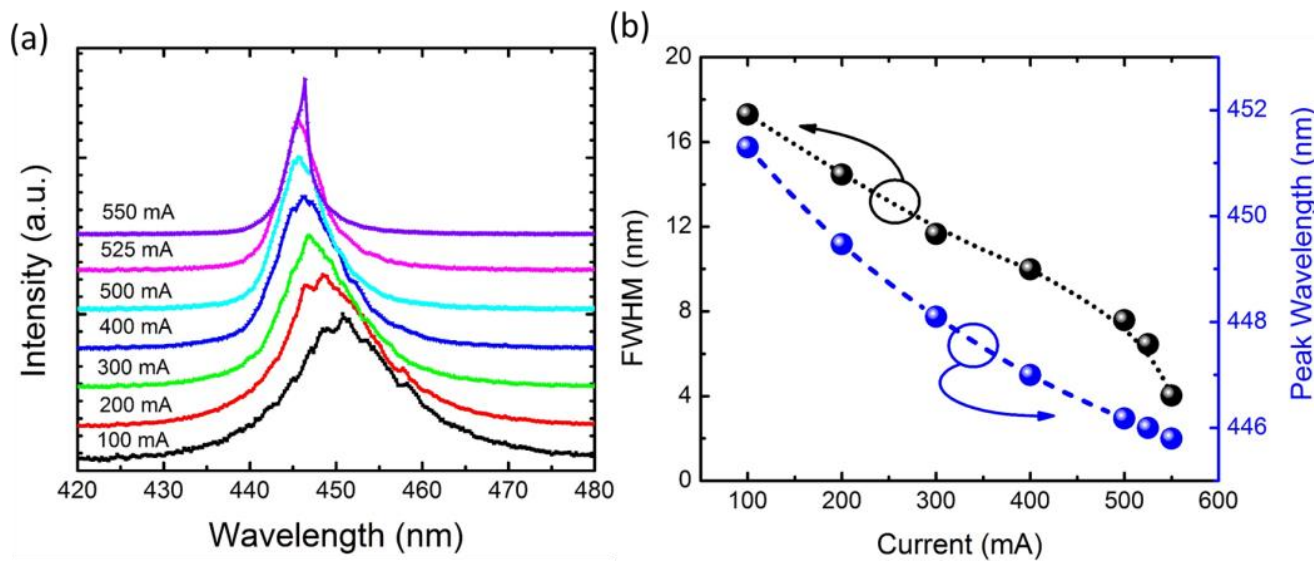

Figure 4. Plots of: (a) emission spectra collected from the edge of the SLD under different injection currents, and (b) emission peak full-width at half-maximum (FWHM) and wavelength as a function of injection current. 
The reducing of full-width at half-maximum (FWHM) of the emission peak from $17.3 \mathrm{~nm}, 11.7 \mathrm{~nm}, 7.6 \mathrm{~nm}$ to $4.0 \mathrm{~nm}$ at an increasing ISLD from $100 \mathrm{~mA}, 300 \mathrm{~mA}, 500 \mathrm{~mA}$ to $550 \mathrm{~mA}$ is evidenced in Figure 4(b). Our SLD shows a large spectral linewidth at 500mA, with EL peak FWHM of $>7 \mathrm{~nm}$ and optical power $>120 \mathrm{~mW}$, which is an advantage for micro-projection and SSL applications. Since the peak FWHM of an InGaN/GaN QW based LD at $450 \mathrm{~nm}$ is typically $<1 \mathrm{~nm}$, the SLD is confirmed to be operating at ASE regime at an $\mathrm{I}_{\mathrm{SLD}}$ up to $550 \mathrm{~mA}$. A blueshift of the emission peak from $451 \mathrm{~nm}$ to $446 \mathrm{~nm}$ at an increasing $\mathrm{I}_{\mathrm{SLD}}$ from $100 \mathrm{~mA}$ to $550 \mathrm{~mA}$ is also measured. This blue shift is attributed to the band filling effect in the InGaN/GaN QW SLD.

\section{SLD BASED PHOSPHOR CONVERTED WHITE LIGHT}

Following the electrical characterization of the SLD, we investigated the utilization of SLD for the white light generation in solid-state lighting applications by using the blue InGaN SLD to excite a YAG:Ce ${ }^{3+}$ phosphor embedded in a silicone rubber. Figure 5 shows the schematic of the setup.

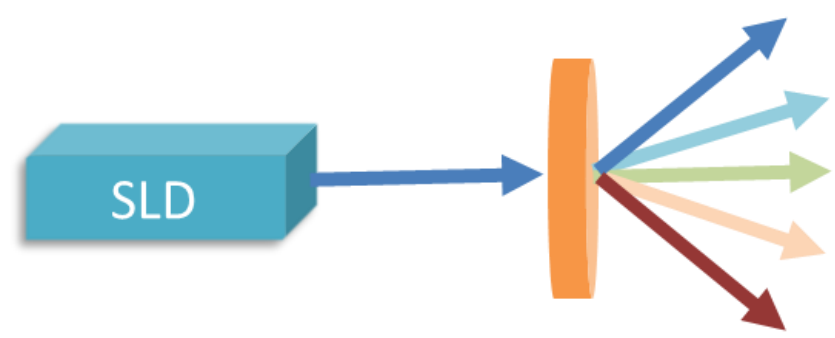

Figure 5. Schematic of the SLD-based, phosphor converted white light source.

The spectrum and white light characteristics of the generated white light were measured and analyzed using a GL Spectis 5.0 Touch spectrometer. Figure 6 exhibits the white light spectra generated by the SLD and the comparison with that generated by a blue-emitting LED and LD. It can be observed that both LED, SLD, and LD are effective in exciting the yellow YAG phosphor. The generated white light is a combination of the InGaN LED/SLD/LD emitted blue light and the phosphor converted yellow light.



Figure 6. Spectra of the white light generated using blue-emitting LED, SLD, and LD with yellow YAG phosphor. 
The color rendering index (CRI) and correlated color temperature (CCT) are important parameters to evaluate the quality of white light. The CRI is a quantitative measure of the ability of a light source to accurately render all visible wavelength in the color spectrum when compared to perfect reference light, such as the sunlight. The CCT is a specification of the color appearance of the light emitted by a light source, relating its color to the color of light from a reference source when heated to a particular temperature, which is measured in degrees Kelvin (K). Besides, the CIE 1931 color space is a widely used method to quantitatively define the color of emitted light and its link with perceived colors in human vision. Hence, the x-y coordinates in the CIE 1931 space chromaticity diagram are of interest in the study the emission property of a light source. The CRI, CCT and CIE 1931 coordinates of the three white light scenarios are summarized in Table 2.

Table 2. Comparison of CRI, CCT and CIE 1931 coordinates of white light generated based on a blue LED, SLD, and LD.

\begin{tabular}{|c|c|c|c|}
\hline & CRI & CCT & CIE 1931 coordinates \\
\hline LED based white light & 69.3 & $4620 \mathrm{~K}$ & $(0.3594,0.3775)$ \\
\hline SLD based white light & 68.9 & $4340 \mathrm{~K}$ & $(0.3711,0.3895)$ \\
\hline LD based white light & 64.7 & $4243 \mathrm{~K}$ & $(0.3779,0.4038)$ \\
\hline
\end{tabular}

The corresponding chromaticity diagram (CIE 1931) coordinates of the three white light scenarios are shown in Figure 7. All three scenarios generate cool white light and the SLD based white light shows an enhanced CRI compared to LD based white light. Both LED and SLD based white light exhibits a similar CRI. The CRI can be further improved by engineering the phosphor mixture, such as combining green and red phosphors, and introducing a broadband phosphor material. But nonetheless, the results suggest that GaN-based SLDs outperforms LDs in generating high-quality white light using the same phosphor.

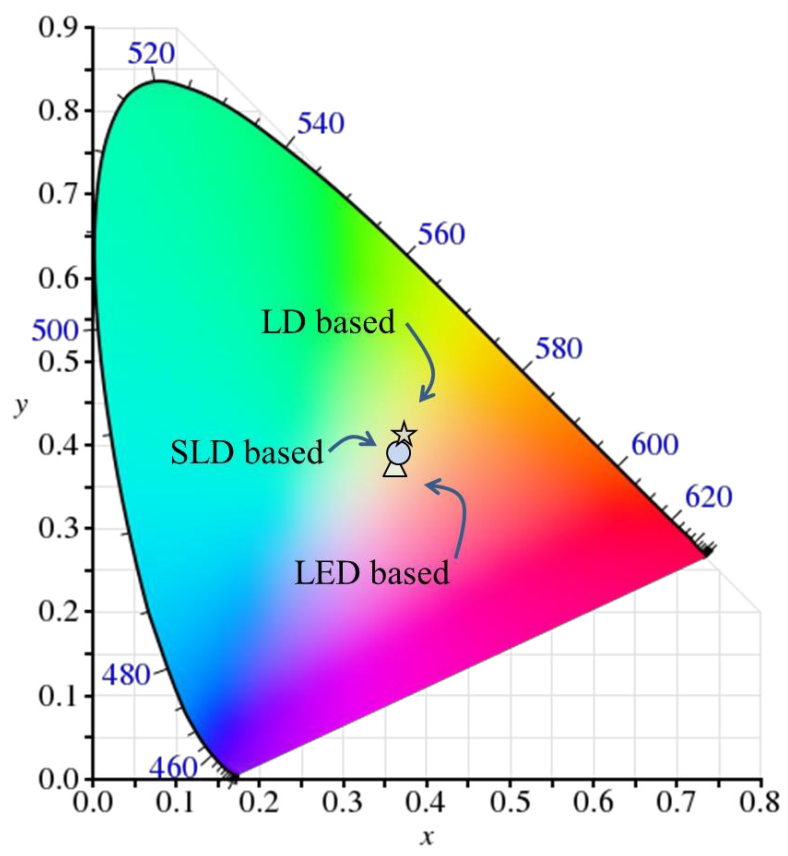

Figure 7. The chromaticity coordinates of the white light generated using blue-emitting LED, SLD, and LD with yellow YAG phosphor.

In addition to the spectral characteristics of the white light, the far-field emission pattern of the white light source is another important factor for illumination applications. The emission pattern was measured by collecting the optical 
power at different observation angle, i.e. the intensity profile, of the white light source, as shown in Figure 8. Since the same phosphor rubber and configuration is used for all three scenarios and there is no diffusing element presented in the setup, the difference of the far field emission pattern is solely attributed to the effect of the beam angle of the light emitters, which refer to the LED, SLD or LD. For instance, LED, as a surface emitter, exhibits a Lambertian emission pattern, where the intensity profile is proportional to the cosine of the emission angle [33]. Both SLD and LD are edge emitter, and narrower beam angles are expected compared to that of the LED. The SLD based white light shows a parabolic-like emission pattern, making it easier to be engineered for both fiber coupling applications and free-space illumination applications. As for LD based white light, a very narrow radiation pattern is observed, suggesting a proper diffusion optics is required before it can be used as a light source for SSL.

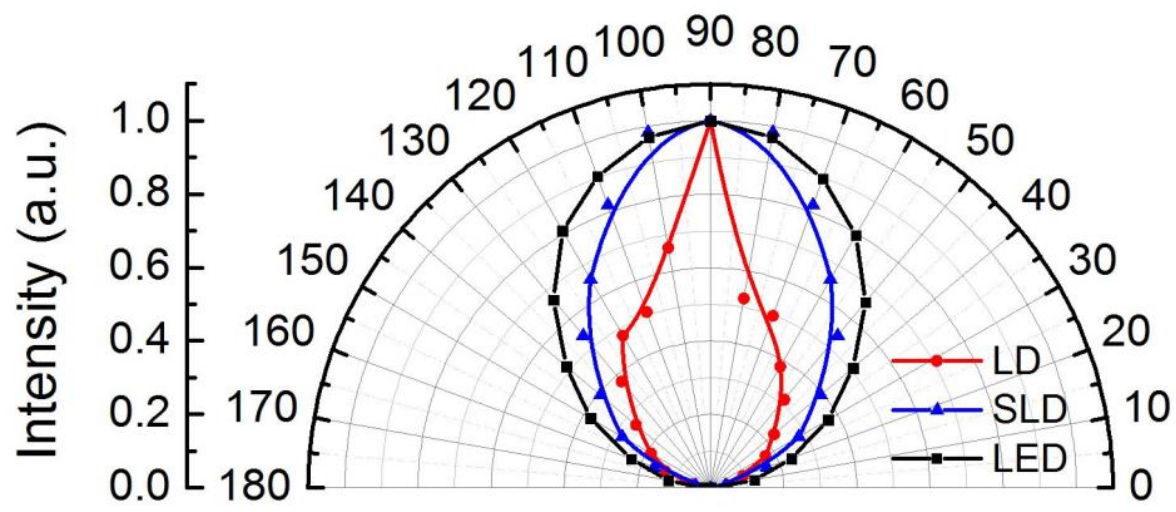

Figure 8. Far-field emission patterns of the white light source based on the blue-emitting LED, SLD and LD.

\section{USING SLD AS A TRANSMITTER FOR VISIBLE LIGHT COMMUNICATIONS}

GaN-based LEDs were utilized as transmitters for free-space VLC. However, the data transmission rate is limited by the modulation bandwidth of the LED, which is only a few megahertz $(\mathrm{MHz})$ or tens of $\mathrm{MHz}$. Using non-return-to-zero onoff keying (NRZ-OOK) modulation scheme, which is a simple and most cost effective one, a data rate of up to 100 Mbit/s can be achieved using LED as the transmitter. Though high-speed micro-LEDs were recently demonstrated, showing a 3-dB modulation bandwidth exceeding $100 \mathrm{MHz}$, but the relative low emission power becomes the limiting factor [34]. The SLD exhibits a much higher modulation bandwidth of $>500 \mathrm{MHz}$ [17], suggesting SLD as a promising transmitter in VLC systems.

To evaluate the SLD based VLC link, a $2^{10}-1$ pseudorandom binary sequence (PRBS) data stream was generated using the pattern generator in the Agilent J-BERT N4903B high-performance serial bit error rate tester (BERT). The data stream was amplified and combined with DC bias using a bias-tee to modulate the SLD. The emitted light was received by a $\mathrm{Si}$ avalanche photodetector and analyzed using the BERT and an Agilent 86100C digital communication analyzer.

(a)



(b)

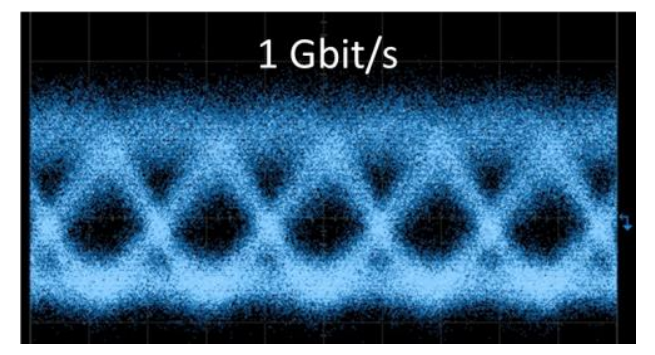

Figure 9. Eye diagrams of the VLC link using SLD as the transmitter operating at a data rate of: (a) 622 Mbit/s, and (b) 1 Gbit/s using on-off keying (OOK) modulation scheme. 
The SLD used has a similar layer structure as the one presented early on, but it contains $\operatorname{In}_{0.1} \mathrm{Ga}_{0.9} \mathrm{~N}$ QW for generating violet light and a top-N-contact design for high-speed operation. At a data rate of $622 \mathrm{Mbit} / \mathrm{s}$ and $1 \mathrm{Gbit} / \mathrm{s}$, the VLC link using SLD as the transmitter exhibits a BER of $4 \times 10^{-4}$ and $8.4 \times 10^{-4}$, respectively, well passes the forward error correction (FEC) limit of $3.8 \times 10^{-3}$. The corresponding eye diagrams in Figure 9 show a clear open eye, suggesting the SLD being an attractive competitor for VLC applications.

\section{CONCLUSIONS}

In summary, the recent advances of III-nitride violet-blue emitting superluminescent diodes, a novel InGaN/GaN QW based SLD on semipolar GaN substrate and its application for solid-state lighting and visible-light communication systems have been presented in this paper. The presented $450 \mathrm{~nm}$ emitting SLD has a high optical power of $>200 \mathrm{~mW}$ with a broad emission peak FWHM of $>7 \mathrm{~nm}$ at an optical power of $100 \mathrm{~mW}$. This lead to a white light source with a CRI of 68.9 and a CCT of $4340 \mathrm{~K}$ when using the blue emitting SLD exciting the yellow YAG phosphor plate. The SLD based white light offers improved white light quality compared to that of the LD-based counterpart, from the aspects of CRI, CCT, and far-field emission pattern. As a transmitter in VLC system, the SLD is able to support much higher data rate (> Gbit/s) for free-space communication compared to the system based on LEDs. Therefore, the GaN-based violetblue SLD offers a combination of the advantages of both LEDs and LDs, making it a promising candidate for the best light source

\section{ACKNOWLEDGEMENTS}

The authors acknowledge the financial support from King Abdulaziz City for Science and Technology (KACST) Grant No. KACST TIC R2-FP-008, and KACST-KAUST-UCSB Solid-State Lighting Program. This work is partially supported by King Abdullah University of Science and Technology (KAUST) baseline funding (BAS/1/1614-01-01).

\section{REFERENCES}

[1] Nakamura, S., Senoh, M., Iwasa, N., and Nagahama, S.-i., "High-power InGaN single-quantum-well-structure blue and violet light-emitting diodes," Appl. Phys. Lett., 67(13), 1868-1870 (1995).

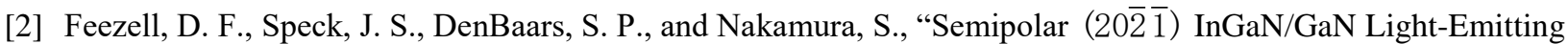
Diodes for High-Efficiency Solid-State Lighting," Journal of Display Technology, 9(4), 190-198 (2013).

[3] Zhao, Y. J., Oh, S. H., Wu, F., Kawaguchi, Y., Tanaka, S., Fujito, K., Speck, J. S., DenBaars, S. P., and Nakamura, S., "Green Semipolar $(20 \overline{2} \overline{1})$ InGaN Light-Emitting Diodes with Small Wavelength Shift and Narrow Spectral Linewidth,” Appl. Phys. Express, 6(6), 062102 (2013).

[4] Shen, C., Ng, T. K., and Ooi, B. S., "Enabling area-selective potential-energy engineering in InGaN/GaN quantum wells by post-growth intermixing," Opt. Express, 23(6), 7991-7998 (2015).

[5] Mishra, P., Janjua, B., Ng, T. K., Shen, C., Salhi, A., Alyamani, A. Y., El-Desouki, M. M., and Ooi, B. S., "Achieving Uniform Carrier Distribution in MBE-Grown Compositionally Graded InGaN Multiple-QuantumWell LEDs," IEEE Photonics Journal, 7(3), 2300209 (2015).

[6] Kang, C. H., Shen, C., M. Saheed, M. S., Mohamed, N. M., Ng, T. K., Ooi, B. S., and Burhanudin, Z. A., "Carbon nanotube-graphene composite film as transparent conductive electrode for GaN-based light-emitting diodes,” Appl. Phys. Lett., 109(8), 081902 (2016).

[7] Nakamura, S., "GaN-based blue/green semiconductor laser," IEEE J. Sel. Top. Quant, 3(2), 435-442 (1997).

[8] Shuji, N., Masayuki, S., Shin-ichi, N., Naruhito, I., Takao, Y., Toshio, M., Hiroyuki, K., and Yasunobu, S., "InGaN-Based Multi-Quantum-Well-Structure Laser Diodes," Jpn. J. Appl. Phys. Pt. 2, 35(1), L74-L76 (1996).

[9] Shen, C., Ng, T. K., Leonard, J. T., Pourhashemi, A., Oubei, H. M., Alias, M. S., Nakamura, S., DenBaars, S. P., Speck, J. S., Alyamani, A. Y., Eldesouki, M. M., and Ooi, B. S., "High-Modulation-Efficiency, Integrated Waveguide Modulator-Laser Diode at 448 nm," ACS Photonics, 3(2), 262-268 (2016).

[10] Strauss, U., Hager, T., Bruderl, G., Wurm, T., Somers, A., Eichler, C., Vierheilig, C., Loffler, A., Ristic, J., and Avramescu, A., "Recent advances in c-plane GaN visible lasers," Proc. SPIE 8986, 89861L (2014). 
[11] Crawford, M. H., "LEDs for Solid-State Lighting: Performance Challenges and Recent Advances,” IEEE J. Sel. Top. Quant, 15(4), 1028-1040 (2009).

[12] Pimputkar, S., Speck, J. S., DenBaars, S. P., and Nakamura, S., "Prospects for LED lighting," Nat. Photonics, 3(4), 180-182 (2009).

[13] Tsonev, D., Videv, S., and Haas, H., "Towards a $100 \mathrm{~Gb} / \mathrm{s}$ visible light wireless access network," Opt. Express, 23(2), 1627-1637 (2015).

[14] Wang, Y. Q., Yang, C., Wang, Y. G., and Chi, N., "Gigabit polarization division multiplexing in visible light communication," Opt. Lett., 39(7), 1823-1826 (2014).

[15]Lee, C., Shen, C., Oubei, H. M., Cantore, M., Janjua, B., Ng, T. K., Farrell, R. M., El-Desouki, M. M., Speck, J. S., Nakamura, S., Ooi, B. S., and DenBaars, S. P., "2 Gbit/s data transmission from an unfiltered laser-based phosphor-converted white lighting communication system," Opt. Express, 23(23), 29779-29787 (2015).

[16] Shen, C., Guo, Y., Oubei, H. M., Ng, T. K., Liu, G., Park, K.-H., Ho, K.-T., Alouini, M.-S., and Ooi, B. S., "20meter underwater wireless optical communication link with 1.5 Gbps data rate," Opt. Express, 24(22), 2550225509 (2016).

[17] Shen, C., Ng, T. K., Leonard, J. T., Pourhashemi, A., Nakamura, S., DenBaars, S. P., Speck, J. S., Alyamani, A. Y., El-Desouki, M. M., and Ooi, B. S., "High-brightness semipolar ( $20 \overline{2} \overline{1})$ blue InGaN/GaN superluminescent diodes for droop-free solid-state lighting and visible-light communications," Opt. Lett., 41(11), 2608-11 (2016).

[18]Rossetti, M., Napierala, J., Matuschek, N., Achatz, U., Duelk, M., Velez, C., Castiglia, A., Grandjean, N., Dorsaz, J., and Feltin, E., "Superluminescent light emitting diodes - the best out of two worlds,"Proc. SPIE 8252,825208 (2012).

[19] Khan, M. Z. M., Ng, T. K., and Ooi, B. S., "High-Performance 1.55- $\mu$ m Superluminescent Diode Based on Broad Gain InAs/InGaAlAs/InP Quantum Dash Active Region,” IEEE Photonics Journal, 6(4), 1600108 (2014).

[20] Khan, M. Z. M., Alhashim, H. H., Ng, T. K., and Ooi, B. S., "High-Power and High-Efficiency 1.3- $\mu \mathrm{m}$ Superluminescent Diode With Flat-Top and Ultrawide Emission Bandwidth," IEEE Photonics Journal, 7(1), 1600308 (2015).

[21] Shen, C., Lee, C., Ng, T. K., Nakamura, S., Speck, J. S., DenBaars, S. P., Alyamani, A. Y., El-Desouki, M. M., and Ooi, B. S., "High-speed 405-nm superluminescent diode (SLD) with 807-MHz modulation bandwidth," Opt. Express, 24(18), 20281-20286 (2016).

[22]Holc, K., Marona, L., Czernecki, R., Bockowski, M., Suski, T., Najda, S., and Perlin, P., "Temperature dependence of superluminescence in InGaN-based superluminescent light emitting diode structures," J. Appl. Phys., 108(1), 013110 (2010).

[23] Kafar, A., Stanczyk, S., Grzanka, S., Czernecki, R., Leszczynski, M., Suski, T., and Perlin, P., “Cavity suppression in nitride based superluminescent diodes," J. Appl. Phys., 111(8), 083106 (2012).

[24] Castiglia, A., Rossetti, M., Matuschek, N., Rezzonico, R., Duelk, M., Vélez, C., Carlin, J. F., and Grandjean, N., "GaN-based superluminescent diodes with long lifetime." Proc. SPIE 9748, 97481V (2016).

[25] Kafar, A., Stanczyk, S., Targowski, G., Oto, T., Makarowa, I., Wisniewski, P., Suski, T., and Perlin, P., "HighOptical-Power InGaN Superluminescent Diodes with "j-shape" Waveguide," Appl. Phys. Express, 6(9), 092102 (2013).

[26] Rossetti, M., Dorsaz, J., Rezzonico, R., Duelk, M., Velez, C., Feltin, E., Castiglia, A., Cosendey, G., Carlin, J. F., and Grandjean, N., "High Power Blue-Violet Superluminescent Light Emitting Diodes with InGaN Quantum Wells," Appl. Phys. Express, 3(6), 061002 (2010).

[27] Feltin, E., Castiglia, A., Cosendey, G., Sulmoni, L., Carlin, J. F., Grandjean, N., Rossetti, M., Dorsaz, J., Laino, V., Duelk, M., and Velez, C., "Broadband blue superluminescent light-emitting diodes based on GaN," Appl. Phys. Lett., 95(8), 081107 (2009).

[28] Kafar, A., Stanczyk, S., Wisniewski, P., Oto, T., Makarowa, I., Targowski, G., Suski, T., and Perlin, P., "Design and optimization of InGaN superluminescent diodes," Phys. Status. Solidi. A, 212(5), 997-1004 (2015).

[29] Hardy, M. T., Kelchner, K. M., Lin, Y. D., Hsu, P. S., Fujito, K., Ohta, H., Speck, J. S., Nakamura, S., and DenBaars, S. P., "m-Plane GaN-Based Blue Superluminescent Diodes Fabricated Using Selective Chemical Wet Etching," Appl. Phys. Express, 2(12), 121004 (2009).

[30] Kopp, F., Eichler, C., Lell, A., Tautz, S., Ristic, J., Stojetz, B., Hoss, C., Weig, T., Schwarz, U. T., and Strauss, U., "Blue Superluminescent Light-Emitting Diodes with Output Power above 100mW for Picoprojection," Jpn. J. Appl. Phys., 52(8), 08JH07 (2013). 
[31]Zeng, C., Zhang, S. M., Liu, J. P., Li, D. Y., Jiang, D. S., Feng, M. X., Li, Z. C., Zhou, K., Wang, F., Wang, H. B., Wang, H., and Yang, H., "Characteristics of InGaN-based superluminescent diodes with one-sided oblique cavity facet," Chinese. Sci. Bull., 59(16), 1903-1906 (2014).

[32] Kopp, F., Lermer, T., Eichler, C., and Strauss, U., "Cyan Superluminescent Light-Emitting Diode Based on InGaN Quantum Wells," Appl. Phys. Express, 5(8), 082105 (2012).

[33] Lai, C.-F., Kuo, H.-C., Chao, C.-H., Yu, P., and Yeh, W.-Y., "Structural Effects on Highly Directional FarField Emission Patterns of GaN-Based Micro-Cavity Light-Emitting Diodes With Photonic Crystals," J. Lightwave. Technol., 28(19), 2881-2889 (2010).

[34] Liao, C. L., Ho, C. L., Chang, Y. F., Wu, C. H., and Wu, M. C., "High-Speed Light-Emitting Diodes Emitting at $500 \mathrm{~nm}$ With 463-MHz Modulation Bandwidth," IEEE Electron Device Lett., 35(5), 563-565 (2014). 